\title{
PENGARUH SUPERVISI AKADEMIK KEPALA SEKOLAH TERHADAP PROFESIONALISME GURU MATA PELAJARAN EKONOMI SMA NEGERI DI KABUPATEN KAMPAR
}

\author{
Filma Alia Sari ${ }^{1}$, M. Yogi Riyantama ${ }^{1 *}$ \\ ${ }^{1}$ Program Studi Pendidikan Ekonomi, Fakultas Keguruan dan IImu Pendidikan \\ Universitas Riau, Pekanbaru, Indonesia \\ *m.yogi@lecturer.unri.ac.id ${ }^{1}$
}

Received: January $12^{\text {th }}, 2020$

Revised: March $01^{\text {st }}, 2020$

Accepted: March $03^{\text {th }}, 2020$

\begin{abstract}
This study aims to see the magnitude of the influence of principal academic supervision on the professionalism of teachers in economics. This research is limited to the state high school unit group only, because there are so many private high schools in Kampar Regency. The method used is a survey method with correlational techniques. The population in this study were all 55 teachers of the economy at SMA Negeri Kampar Regency. The data in this study were collected by distributing questionnaires and documentation obtained from the principal. The data analysis technique used is descriptive analysis technique and inferential analysis. As well as using the data requirements test, namely: normality test and linearity test. The results showed that the magnitude of the influence of the principal's academic supervision on the professionalism of teachers in economics was $16.80 \%$, while the remaining $83.20 \%$ was determined by other factors that were not part of this study.
\end{abstract}

Keywords: acedemic supervision; professionalism of teachers; school principal.

\section{PENDAHULUAN}

Kompetensi merupakan suatu kemampuan yang mutlak dimiliki oleh guru mata pelajaran ekonomi agar tugasnya sebagai pendidik dapat terlaksana dengan baik. Kemampuan dan keterampilan tersebut sebagai bagian dari kompetensi profesionalisme guru mata pelajaran ekonomi. Undang-Undang Republik Indonesia Nomor 14 Tahun 2005 Pasal 10 tentang guru mata pelajaran menyatakan bahwa, kompetensi guru meliputi : (1) kompetensi padagogik, (2) kompetensi kepribadian, (3) kompetensi sosial, dan (4) kompetensi profesional yang diperoleh melalui pendidikan profesi. Kompetensi guru mata pelajaran ekonomi juga dapat dibagi menjadi tiga, yaitu (1) teaching performance, (2) profesional quality, dan (3) personal quality. 
Kajian yang dilaksanakan oleh Sain Hanafy, Nursanga dan Hasbi (2019), disimpulkan bahwa supervisi pendidikan berpengaruh secara langsung dalam meningkatkan profesionalisme guru Sekolah Menengah Kejuruan di Kabupaten Takalar, dengan melihat hasil analisis nilai t-hitung $>\mathrm{t}$ - tabel yaitu 2,268 $>2,005$ dan taraf signifikansi 0,000 $<0,05$. Selanjutnya, Sussono Hadi, Tukiran, dan Budi Yuwono dalam artikelnya pengaruh supervisi akademik, kompetensi guru dan kedisiplinan terhadap kinerja guru SMA Negeri 3 Slawi Kabupaten Tegal di simpulkan bahwa supervisi akademik, kompetensi guru, kedisiplinan, dan kinerja guru-guru SMA Negeri 3 Slawi sudah sangat baik. Kemudian disebutkan juga hasil penelitian Munawar berjudul Supervisi Akademik: mengurai problematika profesionalisme guru di sekolah dalam kedudukannya sebagai supervisor, kepala sekolah memiliki kewajiban untuk membina guru di lembaganya agar menjadi pendidik dan pengajar yang baik, profesional sesuai dengan harapan semua pihak. Supervisi akademik yang dilakukan oleh kepala sekolah harus dilaksanakan dengan penuh komitmen tuntuk melakukan perbaikan dan peningkatan profesionalisme guru dengan memperhatikan prinsip objektivitas dan continous improvement.

Melalui kegiatan supervisi yang dilakukan kepala sekolah secara sistematis, terprogram, dan berkelanjutan diharapkan berbagai kesulitan guru mata pelajaran ekonomi ketika proses pembelajaran akan dapat diatasi, dan pada akhirnya tujuan pembelajaran akan tercapai secara optimal. Dalam situasi demikian, maka pengawasan terhadap sekolah pasti berbeda model dan pendekatannya.

Berdasarkan pengamatan penulis ke sejumlah guru mata pelajaran ekonomi SMA Negeri Kabupaten Kampar, dijumpai fenomena antara lain: kurangnya semangat kerja dalam melaksanakan tugas, kurangnya memberikan penghargaan kepada guru mata pelajaran ekonomi, persiapan mengajar guru mata pelajaran ekonomi belum tertata dengan baik termasuk etos kerja yang perlu ditingkatkan, kurangnya perhatian kepala sekolah dalam menjalankan visi dan misi sekolah, belum terlaksana tupoksi masing-masing wakil kepala sekolah. Penelitian ini peneliti batasi hanya untuk SMA Negeri saja, karena begitu banyaknya SMA Swasta di Kabupaten Kampar. Penelitian ini bertujuan untuk mengungkapkan fakta-fakta efektifitas supervisi kepala sekolah terhadap profesionalisme guru 
TUNJUK AJAR: JURNAL PENELITIAN ILMU PENDIDIKAN

Volume 4, Nomor 1, February 2021

P-ISSN: 2615-062X

E-ISSN: 2622-3554

http://dx.doi.org/10.31258/ita.v4i1.57-72

mata pelajaran ekonomi. Kontribusi dari penelitian ini adalah untuk memperoleh informasi tentang pengaruh supervisi kepala sekolah terhadap profesionalisme guru mata pelajaran ekonomi di SMA Kabupaten Kampar.

\section{KAJIAN TEORITIS}

\section{Guru Mata Pelajaran Ekonomi}

Menurut Sudarman Danim dan Howard M. Vollmer dan Donald L. Mills (2010), bahwa profesionalisme adalah suatu pekerjaan yang menuntut kemampuan intelektual khusus yang diperoleh melalui kegiatan belajar dan pelatihan yang bertujuan untuk menguasai keterampilan atau keahlian dalam melayani atau memberikan advis pada orang lain dalam memperoleh upah dan gaji tertentu. Sedangkan profesionalisme menurut rumusan Undang-undang Nomor 14 Tahun 2005 Bab I Pasal I ayat 4, digambarkan sebagai pekerjaan atau kegiatan yang dilakukan oleh seseorang dan menjadi sumber penghasilan kehidupan yang memerlukan keahlian, kemahiran, dan kecakapan yang memenuhi standar mutu dan norma tertentu serta memerlukan pendidikan profesi. Seorang guru harus mampu menciptakan sikap profesionalisme pada dirinya sehingga dapat mencapai tujuan pendidikan nasional.

Dalam sambutan pengarahan pada lokakarya yang membahas para pendidik calon guru yang diselenggarakan di Tokyo, tertera sebagai berikut : "This expanded function requires a boardening and deeping of the teacher's own knowledge and understanding. He must be attuned to both the cultural milieu of the childeren and tto contemporary currents of thought. It alsorequires that the teacher see him self not as a prime sourdapce of knowledge, but as an orchestrator, an imaginative designer and organizing learning experiences. The new role visualizes the teacheras as promotor, facilitator, organizer, improviser, and manager of learning (APEID, 2012). Berdasarkan definisi di atas, maka dapat ditarik kesimpulan bahwa profesionalisme adalah suatu pekerjaan atau keahlian yang mensyaratkan kompetensi intelektualitas, sikap dan keterampilan tertentu yang diperolah melalui proses pendidikan secara akademis. 


\section{Kepala Sekolah}

Menurut Wahyu Sumidjo ( 2003, 420), secara sederhana kepala sekolah dapat didefinisikan sebagai seorang tenaga fungsional guru yang diberi tugas untuk memimpin suatu sekolah dimana diselenggarakan proses belajar menggajar atau tempat dimana terjadi interaksi antara guru yang memberi pelajaran dan siswa yang menerima pelajaran. Kepala sekolah adalah jabatan pemimpin yang tidak bisa diisi oleh orang tanpa didasarkan atas pertimbangan. Oleh sebab itu, kepala sekolah pada hakikatnya adalah pejabat formal sebab pengangkatannya melalui suatu proses dan prosedur yang didasarkan atas peraturan yang berlaku. Upaya kepala sekolah untuk terus memperbaiki dan meningkatkan mutu pendidikan seakan tidak pernah berhenti. Banyak agenda reformasi yang telah, sedang, dan akan dilaksanakan. Reformasi pendidikan adalah restrukturisasi pendidikan yakni memperbaiki pola hubungan sekolah dengan lingkungannya dan dengan pemerintah pola pengembangan perencanaan, serta pola pengembangan manajerialnya, pemberdayaan guru dan restrukturisasi model-model pembelajaran.

Peraturan Menteri Pendidikan Nasional Nomor 28 Tahun 2010 Pasal 12 tentang Penugasan Guru sebagai Kepala Sekolah/Madrasah menyatakan bahwa guru yang diberi tugas tambahan sebagai kepala sekolah/madrasah dinilai kinerjanya secara berkala setiap tahun dan secara kumulatif selama 4 tahun yang akan dijadikan dasar bagi promosi atau demosi yang bersangkutan. Penilaian kinerja tersebut dilakukan berdasarkan implementasi tugas pokok dan fungsi (tupoksi) sebagai kepala sekolah/madrasah. Disetiap organisasi posisi dan peran pemimpin selalu sangat sentral maju dan mundurnya organisasi sangat tergantung pada sejauh mana pimpinan mampu berimajinasi untuk memajukan organisasinya. Demikian pula dalam konteks sekolah sebagai organisasi, maka posisi kepala sekolah juga sangat penting dalam memajukan lembaga yang dipimpinya. Erat hubungannya antara mutu kepala sekolah seperti disiplin sekolah, iklim budaya sekolah, dan menurunnya perilaku peserta didik. Dalam pada itu kepala sekolah bertanggungjawab atas manajemen pendidikan secara mikro, yang secara langsung berkaitan dengan proses pembelajaran disekolah. Maka dapat dipahami bahwa kepala sekolah sebagai seorang yang bertanggung 
TUNJUK AJAR: JURNAL PENELITIAN ILMU PENDIDIKAN

Volume 4, Nomor 1, February 2021

P-ISSN: 2615-062X

E-ISSN: 2622-3554

http://dx.doi.org/10.31258/ita.v4i1.57-72

jawab atas mutu pendidikan disekolah. Artinya bahwa peran kepala sekolah sebagai pemimpin disekolah sangat berpengaruh terhadap baik buruknya mutu pendidikan disekolah yang ia pimpin.

Kepala sekolah merupakan kunci keberhasilan yang harus menaruh perhatian tentang apa yang terjadi pada peserta didik di sekolah dan apa yang dipikirkan orang tua dan masyarakat tentang sekolah. Peran Kepala sekolah adalah sebagai pemimpin sentral di sekolah yang bertanggung jawab terhadap pengembangan sekolah, peningkatan kualitas sekolah berdasarkan 8 (delapan) standar nasional pendidikan, dan pengembangan profesionalisme sebagai kepala sekolah dengan memenuhi kompetensi; kepribadian dan social; kepemimpinan pembelajaran; pengembangan sekolah; manajemen sumber daya; kewirausahaan; dan supervisi pembelajaran.

\section{Profesionalisme Guru}

Guru adalah pendidik professional yang memiliki tugas utama mendidik, mengajar, membimbing, mengarahkan, melatih, menilai dan mengevaluasi peserta didik pada pendidikan usia dini jalur pendidikan formal, pendidikan dasar, dan pendidikan menengah (Muslich, 2007; Yusrizal, 2020). Tilaar (dalam Sudiyanto: 2008), menyatakan bahwa profesi merupakan pekerjaan dapat pula berwujud sebagai jabatan di dalam suatu hierarki birokrasi yang menuntut keahlian tertentu serta memiliki etika khusus untuk jabatan tersebut serta pelayanan baku terhadap masyarakat. Menurut (UU RI No 14: 2005), profesional adalah pekerjaan atau kegiatan yang dilakukan olehseseorang dan menjadi sumber penghasilan kehidupan yang memerlukan keahlian, kemahiran, dan kecakapan yang memenuhi standar mutu atau norma tertentu serta memerlukan pendidikan profesi.

Pengembangan profesi guru atau pemberdayaan profesi dosen diselenggarakan melalui pengembangan diri yang dilakukan secara demokratis, berkeadilan, tidak diskriminatif, dan berkelanjutan dengan menjunjung tinggi hak asasi manusia, nilai keagamaan, nilai kultural, kemajemukan bangsa, dan kode etik profesi. Kemudian karakteristik profesi dinyatakan oleh Sudiyanto (2008), bahwa enam karakteristik profesi yaitu 1) berdasarkan pada keahlian teknikal 
TUNJUK AJAR: JURNAL PENELITIAN ILMU PENDIDIKAN

Volume 4, Nomor 1, February 2021

P-ISSN: 2615-062X

E-ISSN: 2622-3554

http://dx.doi.org/10.31258/ita.v4i1.57-72

yang diperoleh melalui pendidikan adalah 2) memberikan pelayanan kepada klien 3) adanya norma-norma hubungan antar tenaga profesional-klien 4) orientasi acuan kelompok antar sejawat 5) terdapat struktur kontrol terhadap kinerja 6) memiliki kode etik yang memandu aktivitas-aktivitasnya.

Menurut Zainal Aqib (2009), faktor-faktor yang mempengaruhi profesionalisme guru diantaranya: kualifikasi akademik, pendidikan dan pelatihan, pengalaman mengajar, perencanaan dan pelaksanaan pembelajaran, penilaian dari atasan dan pengawas, prestasi akademik, karya pengembangan profesi, keikutsertaan dalam forum ilmiah, pengalaman organisasi di bidang kependidikan dan sosial, dan penghargaan yang relevan dengan bidang pendidikan. Adapun indikator dari profesionalisme adalah 1) memiliki komitmen pada siswa dalam proses belajar 2) menguasai secara mendalam bahan/mata pelajaran yang diajarkan kepada siswa 3) memiliki tertanggung jawab memantau hasil belajar siswa 4) mampu berpikir sistematis tentang apa yang dilakukan dan belajar dari pengalaman.

\section{Supervisi Kepala Sekolah}

Menurut H.Mukhtar (2009), supervisi adalah suatu usaha mengkondisikan dan membimbing secara kontinu pertumbuhan guru di sekolah baik secara individu maupun kelompok. Supervisi merupakan suatu proses bimbingan yang bertujuan untuk membantu pengembangan professional guru /calon guru khususnya dalam penampilan mengajar berdasarkan observasi dan analisis data secara teliti dan objektif sebagai pegangan untuk perubahan tingkah laku mengajar.

Menurut Purwanto (2000), supervisi adalah suatu aktifitas pembinaan yang direncanakan untuk membantu para guru dan pegawai sekolah lainnya dalam melakukan pekerjaan secara efektif. Sedangkan Manullang (2005), menyatakan bahwa supervisi merupakan suatu proses untuk menerapkan pekerjaan apa yang sudah dilaksanakan, menilainya dan bila perlu mengoreksi dengan maksud supaya pelaksanaan pekerjaan sesuai dengan semula. Di dalam Dictionary of Education Good Carter (dalam Sahertian), supervisi adalah usaha dari petugaspetugas sekolah dalam memimpin guru-guru dan petugas-petugas lainnya dalam 
TUNJUK AJAR: JURNAL PENELITIAN ILMU PENDIDIKAN

Volume 4, Nomor 1, February 2021

P-ISSN: 2615-062X

E-ISSN: 2622-3554

http://dx.doi.org/10.31258/ita.v4i1.57-72

memperbaiki pengajaran, termasuk menstimulasi, menyeleksi pertumbuhan jabatan dan perkembangan guru-guru serta merevisi tujuan-tujuan pendidikan, bahan pengajaran dan metode serta evaluasi pengajaran (Sahertian. 2008:17).

Sedangkan menurut Ross (dalam Sudarwan Danim dan Khairil), supervisi adalah pelayanan kepada guru-guru yang bertujuan menghasilkan perbaikan pengajaran, pembelajaran dan kurikulum. Keberhasilan pembelajaran sangat ditentukan oleh pelaksanaan supervisi yang kontinyu dan berkelanjutan (Sudarwan Danim dan Khairil. 2012, 153). Barinto (2012:209), mengatakan bahwa supervisi adalah kegiatan mengamati, mengidentifikasi mana hal-hal yang sudah benar, mana yang belum benar, dan mana pula yang tidak benar, dengan maksud agar tepat dengan tujuan memberikan pembinaan. Menurut Boardman (dalam Danim dan Khairil), supervisi adalah salah satu usaha menstimulir, mengkoordinasi dan membimbing secara kontinyu pertumbuhan guru-guru di sekolah, baik secara individual maupun secara kolektif agar lebih mengerti dan lebih efektif dalam mewujudkan seluruh fungsi pengajaran, dengan demikian mereka dapat menstimulir dan membimbing pertumbuhan tiap-tiap murid secara kontinyu serta mampu dan lebih cakap berpartisipasi dalam masyarakat demokrasi modern.

Menurut Zakiyah Drajat (2016:14), ada tiga manfaat supervisi yaitu manfaat kepemimpinan, manfaat pembinaan dan manfaat pengawasan. Manfaat kepemimpinan kepala sekolah bertindak sebagai pencipta hubungan yang harmonis dikalangan guru-guru dan karyawan, pendorong bagi kepribadian guru dan karyawan sebagai pelaksana kegiatan belajar, pelaksana dalam pengawasan, dan pelaksana dalam penempatan atau pemberian tugas dan tanggung jawab terhadap guru dan karyawan. Manfaat pembinaan berarti kepala sekolah meningkatkan kemampuan profesi guru dalam bidang pengajaran, bimbingan dan penyuluhan dalam bidang pengelolaan kelas. Sedangkan manfaat pengawasan diartikan sebagai membina pengertian melalui komunikasi dua arah lebih menjamin terlaksananya kegiatan sesuai dengan program kerja.Jadi manfaat supervisi adalah untuk perbaikan dan peningkatkan kualitas. Adapun indikator supervisi ini adalah (1) perencanaan supervisi, yang mencakup tentang program perencanaan dan buku catatan instrumen/ jadwal supervisi; (2) pelaksanaan 
supervisi, yang mencakup tentang penentuan sasaran dan teknik supervisi: dan (3) evaluasi, yang mencakup tentang tindak lanjut hasil supervise (Riffa Hijriah. 2011).

Menurut Moh. Badrus Saleh (2012), secara sistematis, supervisi pendidikan adalah pembinaan yang berupa bimbingan atau tuntutan ke arah perbaikan situasi pendidikan pada umumnya dan peningkatan mutu mengajar dan belajar pada khususnya. Supervisi akademik adalah serangkaian kegiatan membantu guru mengembangkan kemampuannya mengelola proses pembelajaran untuk mencapai tujuan pembelajaran. Supervisi akademik tidak terlepas dari penilaian kinerja guru dalam mengelola pembelajaran. Kemendiknas (2010), menyatakan bahwa supervisi akademik merupakan upaya untuk membantu guru mengembangkan kemampuannya dalam mencapai tujuan pembelajaran.

\section{METODE PENELITIAN}

Penelitian ini dilaksanakan pada SMA Negeri Kabupaten Kampar. Metode yang digunakan dalam penelitian ini adalah metode survei dengan teknik korelasional. Teknik ini dilakukan untuk menganalisis pengaruh antara dua variabel bebas dengan variabel terikat. Populasi dalam penelitian ini adalah seluruh guru ekonomi SMA Negeri Kabupaten Kampar yang berjumlah 55 orang. sampel 35 orang (Slovin, $10 \%$ ) dari populasi. Data dalam penelitian ini dikumpulkan dengan melakukan penyebaran angket untuk variabel supervisi, sedangkan untuk variabel kompetensi guru dengan dokumentasi yang diperoleh dari Kepala Sekolah.

Instrumen yang digunakan dalam penelitian ini ada dua yaitu untuk variabel profesional guru (Y) berasal dari Peraturan Menteri Pendidikan Nasional No. 35 Tahun 2010 tentang Petunjuk Teknis Pelaksanaan Jabatan Fungsional Guru dan Angka Kreditnya. Sedangkan variabel supervisi $(X)$ dikembangkan sendiri oleh penulis yang didasarkan pada indikator setiap variabel. Teknik analisis data yang digunakan untuk mengolah data dalam penelitian ini adalah teknik analisis deskriptif dan analisis inferensial. Analisis statistik inferensial dipakai untuk menguji hipotesis yang telah dirumuskan sebelumnya. Sebelum pengujian hipotesis dalam penelitian ini, terlebih dahulu dilakukan pengujian persyaratan 
analisis data. Persyaratan untuk analisis data ini yaitu: uji normalitas, dan uji linieritas.

\section{HASIL PENELITIAN}

\section{Analisis Deskriptif}

Hasil data dokumentasi yang diperoleh dari Kepala Sekolah SMAN Kabupaten Kampar hasil perhitungan indikator dari variabel profesional guru (Y) yang merupakan dari Peraturan Menteri Pendidikan Nasional No. 35 Tahun 2010 yaitu tentang pedagogik, kepribadian, sosial, dan profesional. Data menunjukkan bahwa standar deviasi profesional adalah 93.33 Angka ini masih di bawah ratarata profesional yaitu sebesar 5,84. Artinya, bahwa penyebaran data profesional profesional guru cukup homogen. Guru yang memiliki kompetensi profesional di bawah rata-rata ada sebanyak 15 orang atau sebesar 42,85\%. Artinya, guru memiliki kompetensi profesional berada dalam kategori sedang. Sedangkan yang memiliki kompetensi profesional di atas rata-rata ada sebanyak 20 orang atau sebesar $57,15 \%$. Berdasarkan hasil perhitungan terhadap data porofesional guru secara keseluruhan diperoleh skor empiris terendah yang dicapai responden adalah 40 dan skor tertinggi adalah 54. Dengan demikian, rentang skor empiris adalah sebesar 14. Perhitungan terhadap distribusi skor profesional guru menghasilkan: (1) skor rata-rata $=47,94$, (2) skor nilai tengah $=48,00$ (3) skor modus $=48$ dan (4) skor simpangan baku $=3,153$.

\section{Analisis Statistik Inferensial}

Pengujian ini dilakukan dengan menggunakan uji normalitas KolmogorovSmirnov dengan ketentuan, bahwa apabila nilai signifikansi (sig) atau nilai probabilitas $>0,05$ maka data berdistribusi normal. Dan bila diperoleh nilai signifikansi (sig) atau nilai probabilitas < 0,05 maka data berdistribusi tidak normal. 
TUNJUK AJAR: JURNAL PENELITIAN ILMU PENDIDIKAN

Volume 4, Nomor 1, February 2021

P-ISSN: 2615-062X

E-ISSN: 2622-3554

http://dx.doi.org/10.31258/ita.v4i1.57-72

Tabel 1. Hasil Uji Normalitas Kolmogorov-Smirnov Variabel Supervisi X dan

Profesional Guru Y

One-Sample Kolmogorov-Smirnov Test

\begin{tabular}{|c|c|c|c|}
\hline & & $\begin{array}{c}\text { PROFESIONAL } \\
\text { GURU } Y\end{array}$ & $\underset{X}{\text { SUPERVISI }}$ \\
\hline $\bar{N}$ & & 35 & 35 \\
\hline Normal Parameters ${ }^{a, b}$ & Mean & 3.5626 & 2.9989 \\
\hline & Std. Deviation & .34795 & .16855 \\
\hline Most Extreme Difference & Absolute & .286 & .138 \\
\hline & Positive & .145 & .138 \\
\hline & Negative & -.286 & -.103 \\
\hline Kolmogorov-Smirnov Z & & 1.691 & .817 \\
\hline Asymp. Sig. (2-tailed) & & 077 & .517 \\
\hline
\end{tabular}

a. Test distribution is Normal.

b. Calculated from data.

Berdasarkan Tabel 1 di atas dapat dimaknai uji normalitas KolmogorovSmirnov untuk nilai signifikansi sebagai berikut:

1. Pada variabel supervise dengan nilai sig $0,517(0,517>0,05)$ hal ini berarti data berdistribusi normal.

2. Pada variabel profesional guru diperoleh nilai sig $0,77(0,77>0,05)$ hal ini berarti data berdistribusi normal.

Selanjutnya uji linieritas bertujuan untuk mengetahui apakah data variabel mempunyai hubungan yang linear atau tidak secara signifikan. Uji ini digunakan sebagai prasyarat statistik parametrik khususnya dalam analisis korelasi atau regresi linear yang termasuk dalam hipotesis assosiatif. Pengujian linieritas menggunakan bantuan program SPSS versi 17.0. Uji linearitas terhadap variabel supervisi dan profesional guru di peroleh sebagai berikut:

Tabel 2. Hasil Uji Homogenitas of Variance Variabel Supervisi dan Profesional Guru Y

\begin{tabular}{lc} 
& Sig \\
\hline Profesional Guru $Y{ }^{*}$ supervisi $X$ & 0,811 \\
\hline
\end{tabular}

Berdasarkan Tabel 2 diperoleh nilai signifikansi (sig) Deviation from Linearity supervisi dengan profesional guru adalah 0,881 lebih besar dari 0,05. Maka dapat 
TUNJUK AJAR: JURNAL PENELITIAN ILMU PENDIDIKAN

Volume 4, Nomor 1, February 2021

P-ISSN: 2615-062X

E-ISSN: 2622-3554

http://dx.doi.org/10.31258/ita.v4i1.57-72

di simpulkan bahwa terdapat hubungan yang linier secara signifikansi antara variabel supervisi kepala sekolah dengan profesional guru ekonomi Kabupaten Kampar.

Selanjutnya pengujian hipotesis dilakukan dengan menggunakan langkahlangkah uji analisis regresi, uji korelasi Pearson, uji persamaan regresi, uji pengaruh dengan menggunakan uji signifikansi (uji hipotesis ada atau tidaknya pengaruh), dan uji besarnya pengaruh melalui Model Summary.

Tabel 3. Uji Korelasi Pearson antara Supervisi terhadap Profesional Guru

\begin{tabular}{cccc}
\hline Variabel & $\mathrm{N}$ & Korelasi Pearson & Sig (2-tailed) \\
\hline $\mathrm{X}-\mathrm{Y}$ & 35 & $0,410^{*}$ & 0,000 \\
\hline
\end{tabular}

${ }^{\star *}$ Correlation is significant at the 0,01 level (2-tailed)

Berdasarkan Tabel 3 tentang uji korelasi Pearson antara supervisi kepala sekolah dengan profesional guru yang dihitung dengan koefisien korelasi, maka diperoleh korelasi Pearson sebesar 0,410 hal ini menunjukan bahwa terdapat hubungan yang signifikan antara supervisi kepala sekolah dengan profesional guru ekonomi Kabupaten Kampar. Dengan $P$ value/Sig yaitu 0,000 $<0,05$ sehingga dapat disimpulkan bahwa terdapat hubungan yang signifikan antara kedua variabel.

Tabel 4. Uji t Hitung Koefisien Variabel Supervisi terhadap Profesional Guru

\begin{tabular}{ccc}
\hline Model & B & Sig \\
\hline (Konstan) & 1,025 & 0,000 \\
supervisi X & 0,846 & \\
\hline
\end{tabular}

Dependent Variabel:Profesional Guru $(Y)$

Berdasarkan Tabel 4 koefisien variabel supervisi dengan profesional guru diperoleh nilai $a=1,025$ dan $b=0,846$ sehingga persamaan regresinya menjadi $Y=$ $1,025+0,846 \mathrm{X}_{1}$, dan persamaan regresi tersebut dapat diartikan bahwa hubungan kedua variabel tersebut adalah signifikan dan linier. Konstanta (a) sebesar 1,025 menyatakan jika tidak ada supervisi kepala sekolah, maka profesional guru ekonomi Kabupaten Kampar sebesar 0,846. Koefisien regresi (b) 
TUNJUK AJAR: JURNAL PENELITIAN ILMU PENDIDIKAN

Volume 4, Nomor 1, February 2021

P-ISSN: 2615-062X

E-ISSN: 2622-3554

http://dx.doi.org/10.31258/ita.v4i1.57-72

sebesar 1,025 artinya bahwa setiap kenaikan satu satuan pada variabel supervisi diikuti dengan peningkatan profesional guru sebesar 0,846 satu satuan.

Dari Tabel koefisien supervisi kepala sekolah terhadap profesional guru diperoleh juga nilai probabilitas yang mana nilai tersebut digunakan untuk menentukan hipotesis diterima atau ditolak. Jika nilai probabilitas lebih besar (sig. $>0,05)$ maka $\mathrm{H}_{0}$ diterima dan $\mathrm{H}_{1}$ ditolak, artinya tidak signifikan. Sedangkan jika nilai probabilitas lebih kecil $(\mathrm{sig}<0,05)$ maka $\mathrm{H}_{0}$ ditolak dan $\mathrm{H}_{1}$ diterima artinya signifikan. Terlihat pada tabel koefisien variabel supervisi terhadap profesional guru nilai probabilitasi sebesar 0,000<0,05 maka $\mathrm{H}_{0}$ ditolak dan $\mathrm{H}_{1}$ diterima sehingga supervisi kepala sekolah berpengaruh secara signifikan terhadap profesional guru ekonomi Kabupaten Kampar. Pengujian hipotesis yang ternyata diterima secara positif dan signifikan, maka perlu pula diketahui berapa besaran pengaruh variabel supervisi terhadap profesional guru. Hal tersebut dapat dijelaskan pada Tabel berikut:

Tabel 5. Pengaruh Variabel Supervisi terhadap Profesional Guru

\begin{tabular}{crrrl}
\hline $\mathbf{R}$ & $\mathbf{R}$ Square & Sig, F Change & Kontribusi (\%) & Tafsiran \\
\hline $0,410^{\mathrm{a}}$ & 0,168 & 0,000 & 16,80 & Rendah \\
\hline
\end{tabular}

Predictors: (Constant),: $X$ Supervisi

I Dependent Variable: (Y) Profesional guru Guru

Pada Tabel 5 diperoleh $R$ Square $\left(r^{2}\right)=0,410$ atau 16,80\%, artinya besar pengaruh variabel supervisi terhadap profesional guru adalah 16,80\% sedangkan sisanya sebesar $83,20 \%$ ditentukan oleh faktor lain yang tidak menjadi bagian dari penelitian ini. Dengan demikian dapat disimpulkan, bahwa pengaruh supervisi terhadap profesional guru memiliki tafsiran atau pengaruh yang rendah.

\section{PEMBAHASAN PENELITIAN}

Pada Tabel 5 diperoleh $R$ Square $\left(r^{2}\right)=0,410$ atau $16,80 \%$, artinya besar pengaruh variabel supervisi kepala sekolah terhadap profesional guru ekonomi Kabupaten Kampar adalah 16,80\% sedangkan sisanya sebesar 83,20\% ditentukan oleh faktor lain yang tidak menjadi bagian dari penelitian ini. Dengan demikian dapat disimpulkan bahwa, pengaruh supervisi kepala sekolah terhadap 
TUNJUK AJAR: JURNAL PENELITIAN ILMU PENDIDIKAN

Volume 4, Nomor 1, February 2021

P-ISSN: 2615-062X

E-ISSN: 2622-3554

http://dx.doi.org/10.31258/ita.v4i1.57-72

profesional guru ekonomi SMA Negeri Kabupaten Kampar memiliki tafsiran atau pengaruh yang rendah.

Hasil penelitian ini juga sesuai dengan pendapat Mohammad Ramadona Rian Wibowo berdasarkan hasil pengujian hipotesis disimpulkan bahwa supervisi kepala sekolah berpengaruh signifikan dan positif terhadap profesional guru pada guru SMP K 1 Penabur Pasar Baru Jakarta Pusat dengan hasil perhitungan korelasi $r=0,7045$. Hasil pengkuadratan $r 2=49,63 \%$ menggambarkan adanya pengaruh supervisi kepala sekolah terhadap professional guru. Pengaruh tersebut dibuktikan dengan hasil uji t bahwa t hitung 5,7026 > t tabel $(33: 0,025)$ sebesar 2,021 sehingga $\mathrm{H}_{0}$ ditolak dan $\mathrm{H}_{\mathrm{a}}$ diterima.

Hasil penelitian Edi Supriono "Pengaruh Supervisi Kepala Sekolah Terhadap Profesional Guru SD Negeri Sekecamatan Sewon Bantul Yogyakarta" hasil penelitian menunjukkan: (1) Pelaksanaan supervisi kepala sekolah yang mencakup persiapan mengajar, penggunaan metode dan instrumen, dan penentuan prosedur evaluasi dan pemanfaat hasil evaluasi tingkat ketepatannya dalam kategori "baik"; (2) Profesional guru yang mencakup penyusunan RPP, membuka pembelajaran, proses pembelajaran, penutupan pembelajaran, evaluasi hasil proses belajar, dan evaluasi pembelajaran tingkat ketepatannya dalam kategori "baik"; dan (3) Pelaksanaan supervisi kepala sekolah memberikan sumbangan efektif sebesar $79 \%$ terhadap profesional guru.

Berdasarkan hasil penelitian Kustiyah menyimpulkan bahwa, supervisi akademik kepala sekolah dengan pendekatan individual memberikan pengaruh terhadap peningkatan prestasi profesional guru SD Candi 01 Kecamatan Candisari Kota Semarang baik komponen perencanaan pembelajaran, pelaksanaan pembelajaran dan evaluasi.

Hasil penelitian ini memiliki kelemahan yang belum dilaksanakan secara efektif oleh kepala sekolah seperti senada dengan hasil penelitian tentang "Pelaksanaan Supervisi Akademik Dalam Peningkatan Profesional Guru Sekolah Dasar Gugus III Sentolo Kulon Progo" oleh Karsiyem, Muhammad Nur Wangid. Hasil penelitian menunjukkan bahwa: (a) supervisi akademik meliputi perencanaan pembelajaran, pelaksanaan pembelajaran, dan penilaian pembelajaran; (b) prinsip-prinsip supervisi akademik meliputi: praktis, objektif, 
TUNJUK AJAR: JURNAL PENELITIAN ILMU PENDIDIKAN

Volume 4, Nomor 1, February 2021

P-ISSN: 2615-062X

E-ISSN: 2622-3554

http://dx.doi.org/10.31258/ita.v4i1.57-72

humanis, kooperatif, kekeluargaan, demokratis, komprehensif, prinsip berkesimbungan belum dilaksanakan, teknik dalam supervisi invidual dan kelompok; (c) tindak lanjut supervisi belum dilakukan dengan optimal, (d) pendukung supervisi kesediaan guru disupervisi, jadwal, seprofesi, kendala supervisi guru terbebani dan banyaknya kegiatan kepala sekolah; (e) upaya memberikan pemahaman supervisi akademik sebagai kebutuhan guru dan jadwal supervisi efektif. Supervisi kepala sekolah yang diprogram secara berkala akan lebih mudah mengelola suasana bekerja yang menyenangkan, sehingga dapat meningkatkan kompetensi profesional guru yang lebih baik.

\section{SIMPULAN DAN REKOMENDASI}

Dari hasil penelitian ini maka diperoleh kesimpulan yang dirumuskan bahwa: Supervisi yang dilakukan kepala sekolah berpengaruh positif dan signifikan terhadap profesionalime guru ekonomi SMA Negeri Kabupaten Kampar. Rekomendasi yang dapat diberikan dalam penelitian ini adalah diharapkan tindak lanjutnya kepada para guru agar selalu bekerja sama dengan kepala sekolah dalam hal melaksanakan tugas sesuai dengan program sekolah sehingga tujuan dapat tercapai dengan baik melalui kinerja yang efektif. Para guru diharapkan memperbanyak pelatihan-pelatihan khusus mengenai cara meningkatkan kinerja dengan cara menggiatkan kegiatan yang dapat meningkatkan profesionalismenya. Kepala Sekolah harus memberikan supervisi yang baik kepada para guru. Sebagai seorang inovator, kepala sekolah harus memiliki strategi tepat untuk menjalin hubungan harmonis dengan lingkungan, mencari gagasan, mengintegrasikan kegiatan, memberikan teladan dan mengembangkan model pembelajaran inovatif.

\section{DAFTAR PUSTAKA}

APEID. (2012). Guru Mata Pelajaran Ekonomi Profesional. Bandung: Refika Aditama.

Asmani Jamal Ma'mur. (2012). Tips Efektif Supervisi Pendidikan. Yogyakarta: Diva . 
TUNJUK AJAR: JURNAL PENELITIAN ILMU PENDIDIKAN

Volume 4, Nomor 1, February 2021

P-ISSN: 2615-062X

E-ISSN: 2622-3554

http://dx.doi.org/10.31258/ita.v4i1.57-72

Burhanuddin Yusak. (2014). Kepemimpinan Kepala Sekolah. Bandung: Pustaka Setia.

Da'i Wibowo. (2009). Pengaruh Supervisi Kepala Sekolah danKompetensi Pedagogik Terhadap Kinerja Guru Mata pelajaran ekonomi Kecamatan Kersana Guru Mata pelajaran ekonomi Kecamatan Kersana Kabupaten Brebes

Liberman. (2012). Profesionalisme Guru Mata Pelajaran Ekonomi. Surabaya: Raja Grafindo Persada.

Ma'ruf. (2011). Supervisi Kepala Sekolah dan Etos Kerja Terhadap Disiplin Guru Mata Pelajaran Ekonomi SMK Lampung Tengah.

Moh.Badrus Saleh. (2012). Supervisi Pendidikan Sekolah. Yogyakarta: Diva.

Moore. (2006). Sertifikasi Profesi Kegunaan di Indonesia. Surabaya.

Mukhtar. (2009). Orientasi Baru Supervisi Pendidikan. Jambi: Gaung Persada Press Group.

PH Slamet. (2006). Kemampuan Profesionalisme Guru Mata Pelajaran Ekonomi dan Tenaga Kependidikan. Bandung: Alfabeta.

Purwanto. (2000). Manajemen Supervisi \& Kepemimpinan Kepala Sekolah. Bandung: Alfabeta.

Safrudin, Nurdin. (2005). Profesionalisme Guru Mata Pelajaran Ekonomi. Surabaya: Raja Grafindo Persada.

Sagala \& Anwar, (2005). (2000). Manajemen Supervisi \& Kepemimpinan Kepala Sekolah. Bandung: Alfabeta.

Suparlan, B. (2005). Model Pembelajaran Ekonomi dan Akuntansi. Jakarta: Pusat Kurikulum.

Sudarman, Danim \& Donal L.Mills. (2010). Pendidik Profesional. Surabaya: Raja Grafindo Persada.

Tafsir, Ahmad. (2012). Pendidik Profesional. Surabaya: Raja Grafindo Persada.

Undang-undang Nomor 14 Tahun 2005 Bab I Pasal I ayat 4.

Waller, Richard. (2013). Orientasi Baru Supervisi Pendidikan. Jambi: Gaung Persada Press Group.

Weber, Max. (1991). Etos Kerja dan Kohesi Soaial. Yogyakarta : Aditya Media. 
TUNJUK AJAR: JURNAL PENELITIAN ILMU PENDIDIKAN

Volume 4, Nomor 1, February 2021

P-ISSN: 2615-062X

E-ISSN: 2622-3554

http://dx.doi.org/10.31258/ita.v4i1.57-72

Yuli Indra Wati. (2012). Supervisi Kepala Sekolah dan Motivasi Kerja Guru Mata Pelajaran Ekonomi Terhadap Kinerja Guru Mata Pelajaran Ekonomi.

Yusrizal, Y. (2020). Peningkatan Kemampuan Guru SDN 006 Sencano Jaya dalam Membuat Rencana Pelaksanaan Pembelajaran (RPP) Berbasis Inkuiri. Tunjuk Ajar: Jurnal Penelitian IImu Pendidikan, 3(2), 130-145. 